
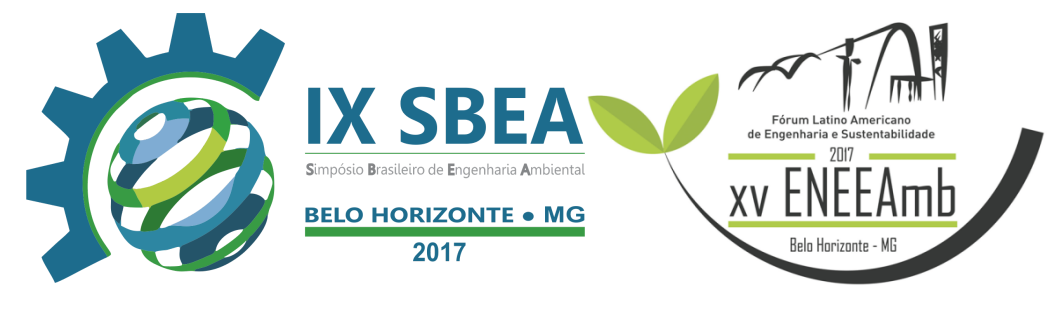

RESÍDUOS SÓLIDOS

\title{
ANÁLISE dA PRODUÇÃO DE BIOGÁS A PARTIR DA BIODIGESTÃO DE RESÍDUOS ORGÂNICOS DOMÉSTICOS
}

Fernanda Cristina de Andrade Silva - fernandaa231@gmail.com

Faculdades Santo Agostinho - FASA SETE

Fernando Augusto Moreira - fam.quimico@gmail.com

Faculdades Santo Agostinho - FASA SETE 


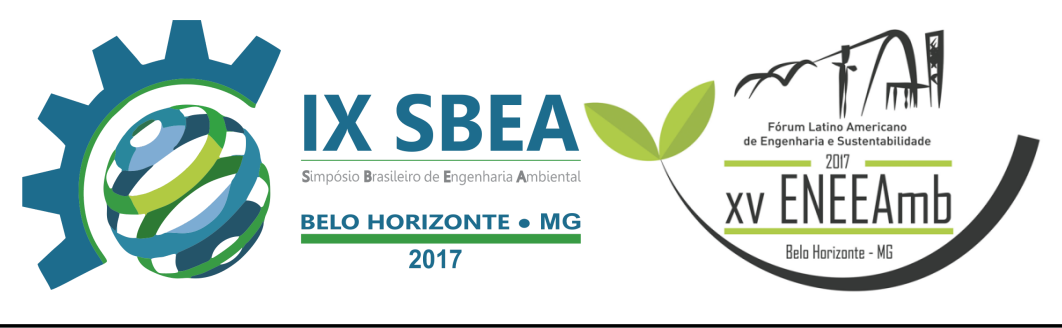

\section{RESUMO}

O aumento da produção de resíduos é considerado um problema de saneamento básico e saúde pública. Se devidamente segregados os resíduos servem de matéria prima na geração de novos produtos. Como é o caso do processo de biodigestão anaeróbica, onde a fração orgânica do resíduo é convertida em biogás e biofertilizante. O objetivo do trabalho foi avaliar a viabilidade de aplicação de um biodigestor para uso residencial na produção de biogás a partir de resíduos domésticos, como alternativa à destinação e ao reaproveitamento dos resíduos orgânicos. Para isto, foi determinada a composição gravimétrica e geração per capita dos mesmos, com posterior processamento em uma câmara de fermentação. A maior parte de resíduos gerados na residência foi de origem orgânica. Sendo que, durante o período analisado, gerou-se 138,175 Kg de resíduos, dos quais $72 \%$ correspondeu a fração orgânica. A produção de biogás obtida no modelo de biodigestor proposto foi de aproximadamente 5,3 L ao dia. A utilização de um biodigestor na residência avaliada não é viável devido a baixa massa de resíduos orgânicos gerados diariamente.

Palavras-chave: biodigestor; carga orgânica; resíduos sólidos domésticos.

\section{INTRODUÇÃO/OBJETIVO}

De acordo com Silva (2009) o aumento da taxa de produção de resíduos sólidos, decorrente do aumento populacional e as atividades industriais, é considerado um problema de saneamento básico e saúde pública. Uma vez que a maioria das cidades brasileiras gera quantidades de resíduos que vão além da capacidade de coletar e armazenar, sem causar danos ao meio ambiente.

Figueiredo (2012) considera que o gerenciamento de resíduos sólidos é um desafio para o poder público. São diversas as maneiras de disposição dos resíduos, sendo os aterros controlados e vazadouros a céu aberto não são indicados para tal fim, uma vez que são as formas mais impactantes ao meio ambiente. Apesar disto, 41,6\% do resíduo produzido no país ainda são dispostos nestas áreas (ABRELPE, 2014). 


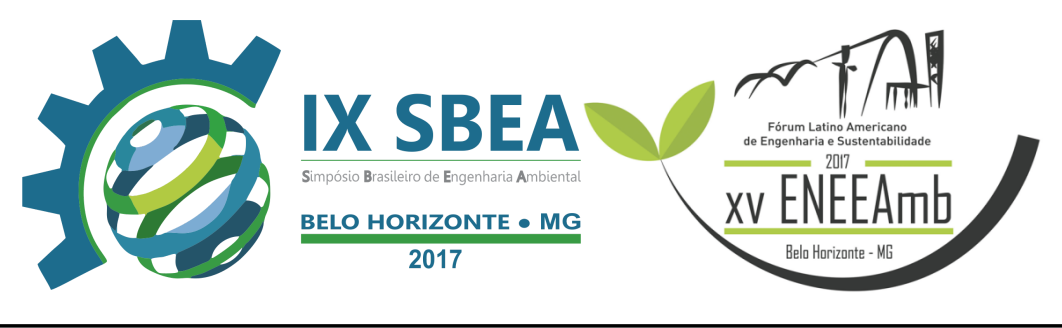

Desde que os resíduos sejam segregados eles podem servir de matéria prima na geração de outros produtos. A fração orgânica dos resíduos pode ser incorporada no processo de biodigestão anaeróbica para produção de biogás. (CUNHA; CAIXETA FILHO, 2002). Este processo é definido por Barros et al. (2009), como um processo de fermentação que ocorre na ausência de oxigênio onde bactérias anaeróbias e metanogênicas sintetizam a matéria orgânica, como os dejetos animais, plantas e resíduos sólidos, em metano e dióxido de carbono.

Conforme pesquisa do IPEA (2012) apesar dos resíduos sólidos domiciliares no Brasil apresentarem um alto percentual de matéria orgânica, as experiências de tratamento desta ainda são incipientes. Reis (2012) propõe que a digestão anaeróbia seja uma alternativa promissora para o tratamento da fração orgânica dos resíduos sólidos, em virtude das altas taxas de produção de biogás do processo.

Devido à problemática dos resíduos e a matriz energética que é baseada em sua maioria na utilização de fontes não renováveis, é necessário o desenvolvimento e aplicação de tecnologias que contribuam de forma sustentável para reutilização dos resíduos e evitem o esgotamento dos recursos naturais não renováveis. Diante disto, o processo de biodigestão anaeróbica de resíduos torna-se uma alternativa importante, uma vez que contribuem para uma destinação correta da fração orgânica de resíduos, e ainda gera como produto o biogás que possui potencial energético.

O objetivo deste trabalho é avaliar a viabilidade de aplicação de um biodigestor para uso residencial na produção de biogás a partir de resíduos orgânicos domésticos, como alternativa a destinação correta de resíduos e ao reaproveitamento sustentável do potencial energético dos mesmos.

\section{METODOLOGIA}

A pesquisa foi realizada entre agosto de 2015 à junho de 2016, em duas etapas. $\mathrm{Na}$ primeira etapa foi realizada a caracterização dos resíduos de uma residência localizada no município de Pedro Leopoldo-MG. 


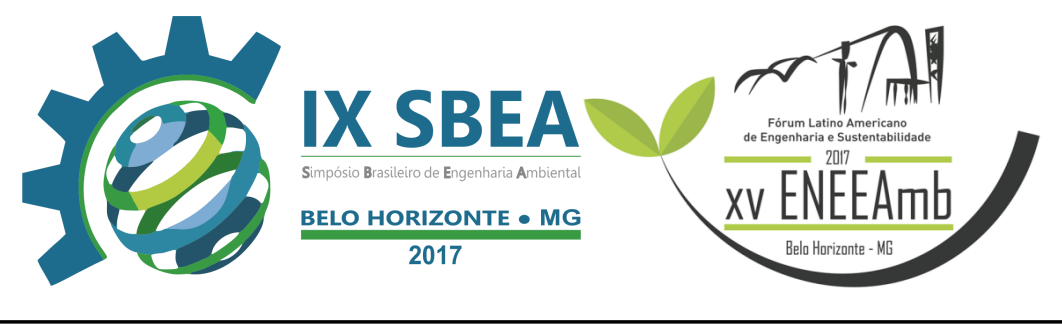

Para a caracterização gravimétrica e geração per capita, os resíduos foram coletados diariamente durante 153 dias, sendo segregados em matéria orgânica, resíduos recicláveis e rejeitos.

A geração de resíduos foi quantificada diariamente, sendo registradas as massas para cada tipo de resíduo. Para a determinação da massa dos resíduos foi utilizada balança digital semi analítica da marca CLINK. Após finalizar o período de caracterização, os dados obtidos foram tabulados em planilha.

$\mathrm{Na}$ segunda etapa foi desenvolvida a montagem do biodigestor e a análise dos resultados da caracterização e geração do biogás. Nesta etapa o trabalho foi conduzido nas instalações da Faculdade Santo Agostinho de Sete Lagoas (FASA SETE), entre Abril e Junho de 2016.

Para o acondicionamento dos resíduos orgânicos foi utilizada uma câmara de fermentação com volume de 20 L. Acoplado a esta câmara, foi adaptado um sistema de tratamento de gás, que fez uso de um filtro de esponja de aço e solução de hidróxido de sódio de concentração equivalente a $1 \mathrm{~mol} / \mathrm{L}$, visando a neutralização dos compostos ácidos e potencialmente corrosivos.

Para quantificar a produção de biogás foram adotados dois métodos. No primeiro método (Figura 1), foi utilizado um compressor para extrair o gás do reservatório de biodigestão e comprimi-lo em um cilindro de $2 \mathrm{Kg}$ e capacidade volumétrica de 5,5 L. A produção do biogás foi quantificada a partir da variação de pressão com um auxílio de um manômetro da marca RECORD®.

Figura 1 - Método 1: Quantização da produção de biogás de utilizando o compressor, botijão e manômetro.

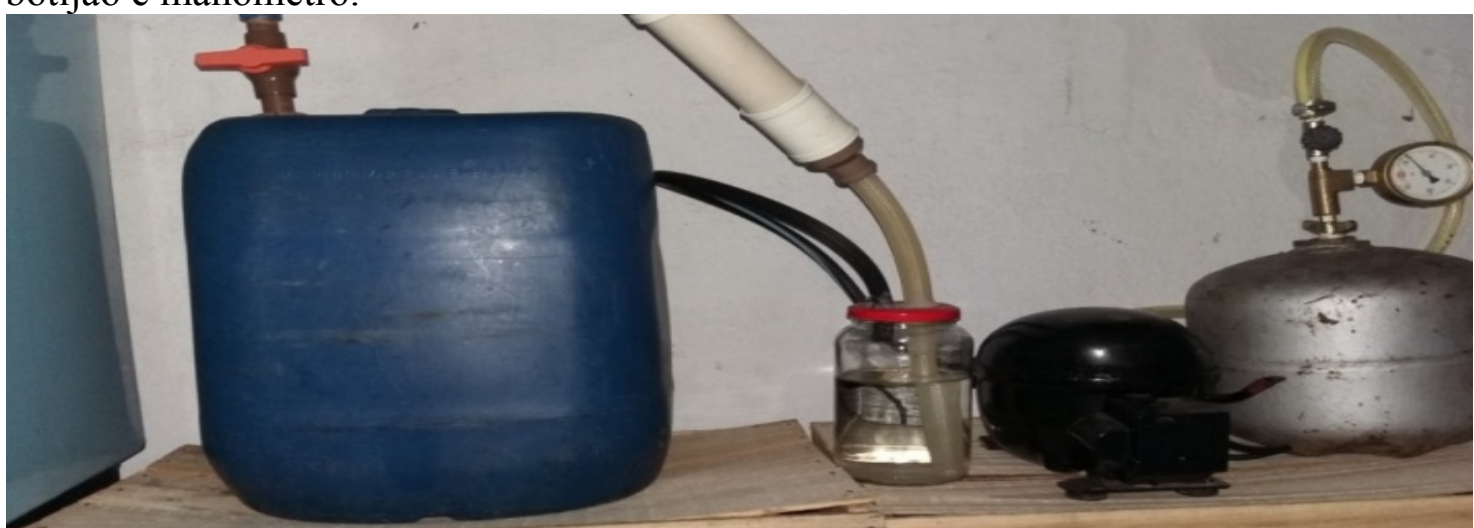

Fonte: SILVA, F.C.A. 

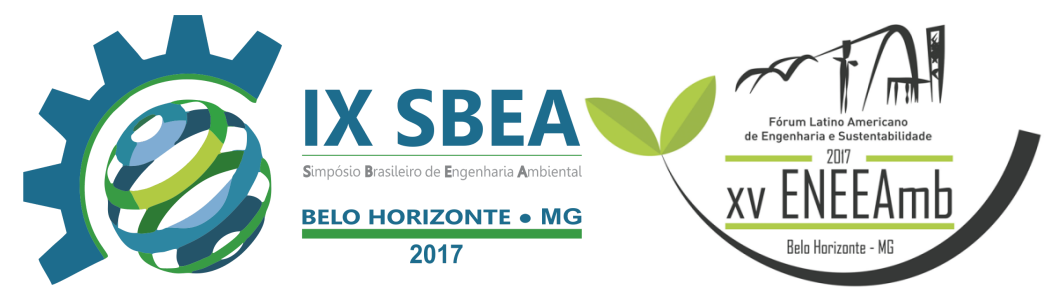

No segundo método (Figura 2), realizou-se a medida a partir da pressão exercida pelo gás em uma coluna d'água. Para isto, encheu-se uma proveta de $1000 \mathrm{~mL}$ com água e colocou a mesma, invertida sobre uma bandeja com água. O volume inicial registrado na proveta foi registrado. A pressão exercida pelo gás produzido desloca o volume da água contida dentro da proveta, ocupando o volume da mesma, podendo assim ser quantificado.

Após a montagem, o biodigestor foi abastecido com resíduos orgânicos composto de restos de alimentos, cascas de vegetais e frutas, devidamente triturados na proporção volumétrica de 1:1 em água, totalizando um volume de 18 litros. Para o abastecimento do biodigestor adotou-se o sistema por batelada, sendo adotada a frequência quinzenal para reabastecimento do reator de fermentação.

Figura 2 - Método 2: Quantização da produção de biogás de utilizando a proveta invertida

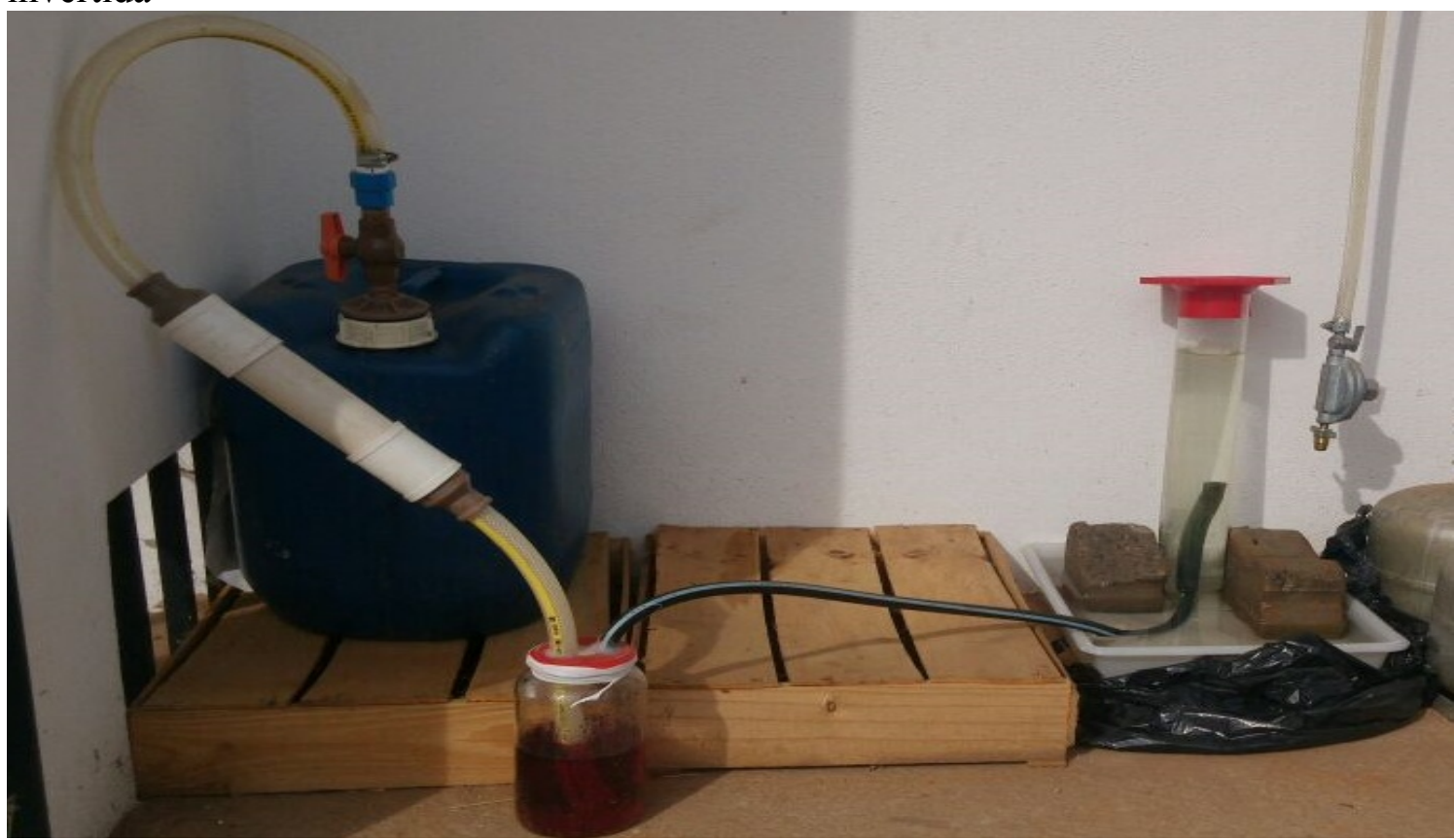

Fonte: SILVA, F. C. A.

No primeiro método as medições da produção do biogás foram realizadas semanalmente, através dos valores registrados no manômetro. 


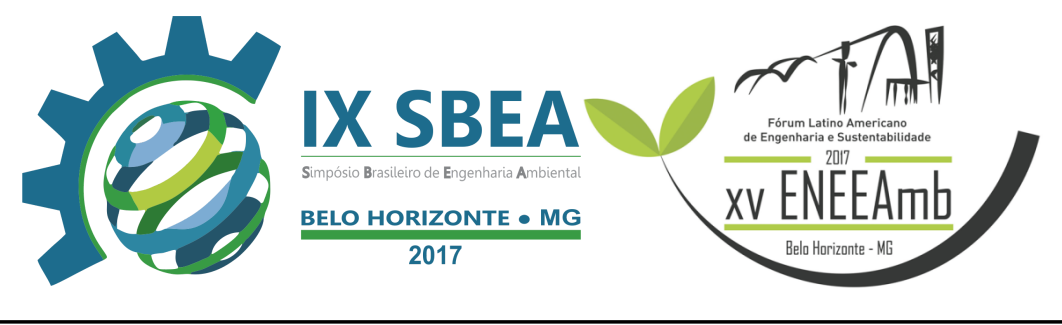

Já para o segundo método as medições da produção do biogás foram realizadas diariamente, através do diagnóstico visual do volume registrado na proveta invertida. Os dados obtidos foram registrados diariamente.

Para a estimativa da produção de biogás foi adotado o método do IPCC (1996, apud NECKER e ROSA, 2013).

Para o dimensionamento do biodigestor, pode-se obter o seu tamanho, através dos cálculos de dimensionamento propostos por Teixeira (2003), Veloso et al., 2010 e Medeiros (1999), apud Potenciano (2012).

Após a estabilização do processo de biodigestão, o biofertilizante foi retirado do biodigestor e foi submetido a análises laboratoriais para determinação de macro e micronutrientes através do método de Espectroscopia de Emissão Óptica com Plasma Acoplado Indutivamente (ICP-OES).

\section{RESULTADOS E DISCUSSÃO}

Conforme estudo pode-se verificar que na residência com o perfil analisado gera-se $0,226 \mathrm{Kg} / \mathrm{habxd}$ de resíduos, sendo $0,163 \mathrm{Kg} / \mathrm{habxd}$ de matéria orgânica. A composição gravimétrica dos resíduos da residência pode ser observado no Gráfico 1:

Gráfico 1 - Composição Gravimétrica

\section{Massa diária $(\mathrm{Kg} / \mathrm{d})$}

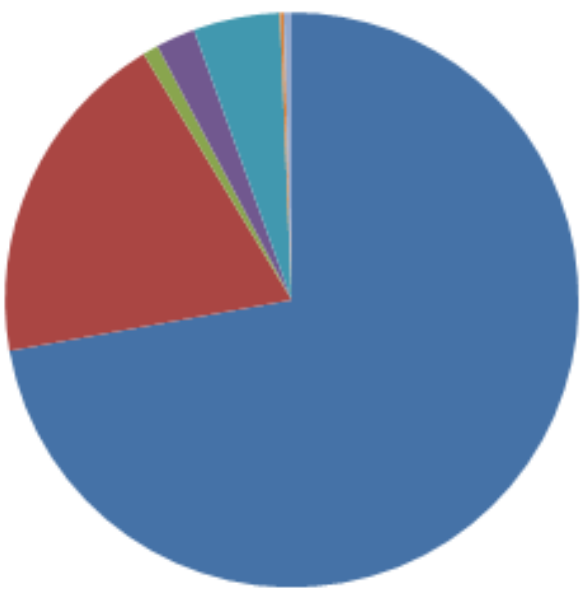

- Orgânico

Rejeito

Metal

- Plástico

- Papel

vidro

Tetra Pak

Fonte: Dados da pesquisa 


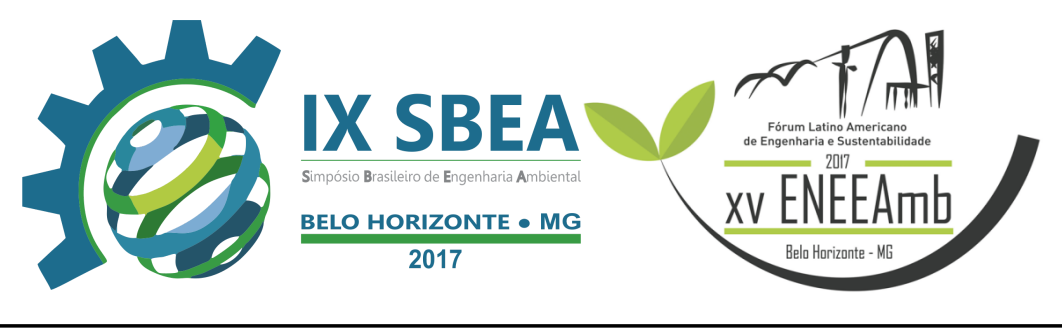

O biodigestor para uso na residência deve ter capacidade volumétrica de $210 \mathrm{~L}$, considerando para abastecê-lo uma massa de resíduo orgânico produzida em uma semana.

A produção de biogás teórica, obtida através da estimativa proposta no método IPCC (1996), apud Necker e Rosa (2013), foi de 81 L, enquanto que a real obtida no modelo de biodigestor proposto foi de 5,3 L. Este valor representa 6,5\% do valor estimado, apresentando uma grande diferença para o valor real. Isto ocorre devido a sensibilidade de um processo de biodigestão, uma vez que a produção de biogás é influenciada por uma série de fatores, sendo que na realidade só pode se obter um valor igual ao estimando caso sejam proporcionadas as mesmas condições observadas no modelo teórico.

O biofertilizante apresenta características semelhantes e em alguns casos apresenta concentração de nutrientes superior as que foram encontradas na literatura pesquisada, o que indica o potencial de aplicação do mesmo na agricultura. Após as análises o biofertilizante apresentou as seguintes concentrações de macro e micro nutrientes (Tabela 1).

Tabela 1 - Análise de macro e micronutrientes do biodigestor

\begin{tabular}{cccc}
\hline Composição & & Digerido & Filtrado \\
\hline & Fósforo & 78,56 & 59,93 \\
& Potássio & 1435,00 & 316,94 \\
Macronutrientes (mg/L) & Cálcio & 119,50 & 92,55 \\
& Magnésio & 60,89 & 41,87 \\
& Enxofre & 80,15 & 60,26 \\
& Cobre & 0,00 & 0,00 \\
Micronutrientes (mg/L) & Ferro & 1,63 & 1,03 \\
& Mangânes & 0,35 & 0,29 \\
& Zinco & 0,72 & 0,42 \\
\hline
\end{tabular}

Fonte: Dados da pesquisa

\section{CONCLUSÕES/RECOMENDAÇÕES}

Com a realização do trabalho foi possível quantificar e caracterizar a composição dos resíduos na residência. Conforme estudo pode-se verificar que na 


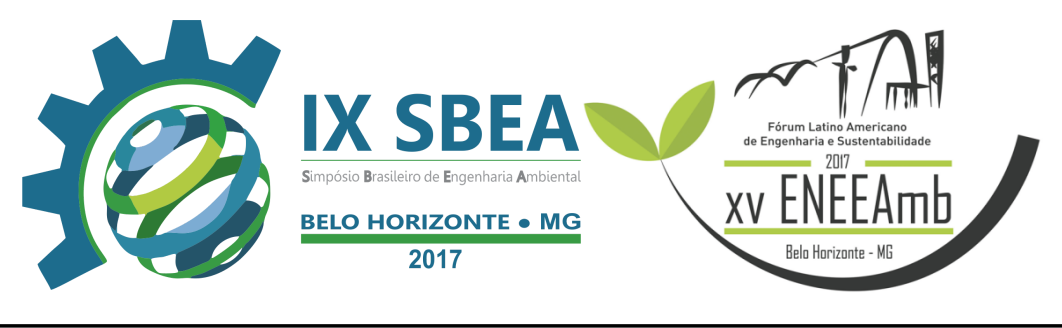

residência com o perfil analisado gera-se $0,226 \mathrm{Kg} /$ hab.d de resíduos, sendo 0,163 $\mathrm{Kg} /$ hab.d de matéria orgânica. Do total de resíduos gerados, $72 \%$ correspondem à matéria orgânica, 19,2\% correspondem aos rejeitos e 8,8\% é o percentual de resíduos potencialmente recicláveis.

O biodigestor para uso na residência deve ter capacidade volumétrica de $210 \mathrm{~L}$, considerando que para abastecê-lo é necessária uma massa de resíduo orgânico produzida em uma semana, o que implica dizer que para ser abastecido em apenas um dia na sua capacidade total, seriam necessárias 28 pessoas gerando a mesma massa de resíduo.

A produção de biogás teórica foi de $81 \mathrm{~L}$, enquanto que a real obtida no modelo de biodigestor proposto foi de 5,3 L, o que representa uma diferença significativa entre as duas situações em decorrência da sensibilidade de um processo de biodigestão anaeróbica.

A utilização de um biodigestor na residência avaliada não é viável, do ponto de vista da obtenção de biogás para substituição de fontes energéticas, como por exemplo, fontes combustíveis, gás de cozinha ou convertida para energia elétrica, uma vez que a baixa produção diária de resíduos orgânicos implica em uma baixa produção de biogás.

O biofertilizante apresenta características semelhantes e em alguns casos apresenta concentração de nutrientes superior as que foram encontradas na literatura pesquisada, o que indica o potencial de aplicação do mesmo na agricultura. Apesar da produção de biogás, não ter apresentado valores satisfatórios o composto obtido apresentou resultados satisfatórios, do ponto de vista de concentração de macro e micronutrientes, onde cria-se a possibilidade de utilização de um resíduo como matéria prima de qualidade para utilização na agricultura. Contribuindo tanto para a redução de volume de resíduos em aterros como para a substituição de agroquímicos que trazem sérios danos ambientais.

Recomenda-se para estudos posteriores a avaliação da produção de biogás voltada não apenas para uma residência, mas para um conjunto de residências visando uma maior produção de biogás. 


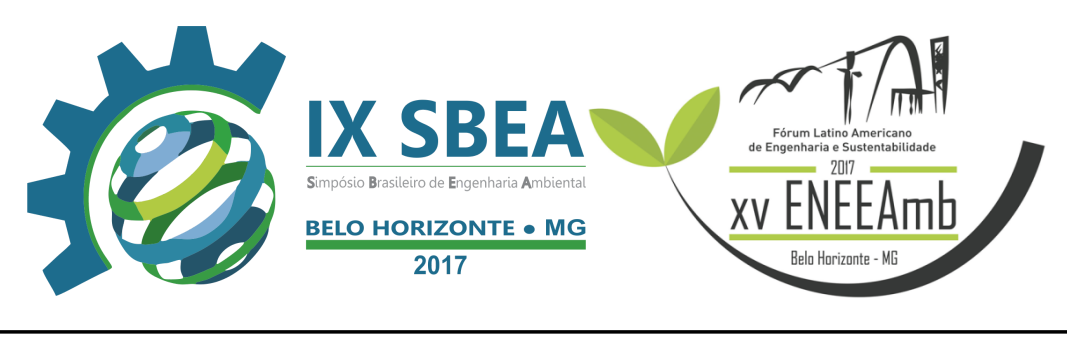

\section{REFERÊNCIAS BIBLIOGRÁFICAS}

ABRELPE. Associação Brasileira de Empresas de Limpeza Pública e Resíduos Especiais. SILVA FILHO, C. R. V. da.Panorama de Resíduos Sólidos no Brasil.Brasil. 2014.

BARROS, R. M. et al. Estudo da produção de biogás da digestão anaeróbia de esterco bovino em um biodigestor. Revista Brasileira de Energia, v. 15, n. 2, p. 95-116, 2009. CUNHA, V.; CAIXETA FILHO, J. V. Gerenciamento da coleta de resíduos sólidos urbanos: estruturação e aplicação de modelo não-linear de programação por metas. Gestão \& Produção, v.9, n.2, p.143-161, 2002.

FIGUEIREDO, J. C. Estimativa de produção de biogás e potencial energético dos resíduos sólidos urbanos em Minas Gerais. 2012. 139 f. Dissertação (Mestrado em Análise e Modelagem de Sistemas Ambientais) - Universidade Federal de Minas Gerais, Belo Horizonte, 2012.

IPEA. INSTITUTO DE PESQUISA ECÔNOMICA APLICADA. MOTA, J. A.; ALVAREZ, Albino Rodrigues. Diagnóstico dos Resíduos Sólidos Urbanos. Relatório de Pesquisa. Brasília. 2012.

NECKER, H. S.; ROSA, A. L. D da. Estimativa teórica da geração de biogás do futuro aterro sanitário de Ji-Paraná-RO. Revista Eletrônica em Gestão, Educação e Tecnologia Ambiental, Santa Maria,v. 17, n. 17, p. 3416-3424, 2013.

POTENCIANO, J. M. J. Análise do dimensionamento de diferentes biodigestores para o tratamento da manipueira. 2012. 52 f. Trabalho de Conclusão de Curso (Graduação) - Universidade Estadual de Goiás, Anápolis, 2012.

REIS, A. dos S. Tratamento de resíduos sólidos orgânicos em biodigestor anaeróbio. 2012. 79 f. Dissertação (Mestrado em Tecnologia Ambiental) Universidade Federal de Pernambuco, Caruaru, 2012.

SILVA, W. R. Estudo cinético do processo de digestão anaeróbia de resíduos sólidos vegetais. 2009. 201 f. Tese (Doutorado em Química Analítica) - Universidade Federal da Paraíba, João Pessoa, 2009.

TEIXEIRA, V. H. Biogás. Curso de Pós-Graduação "Lato Sensu" Especialização a Distância: Fontes Alternativas de Energia. Lavras: UFLA/FAEPE, 2003. 94p. 


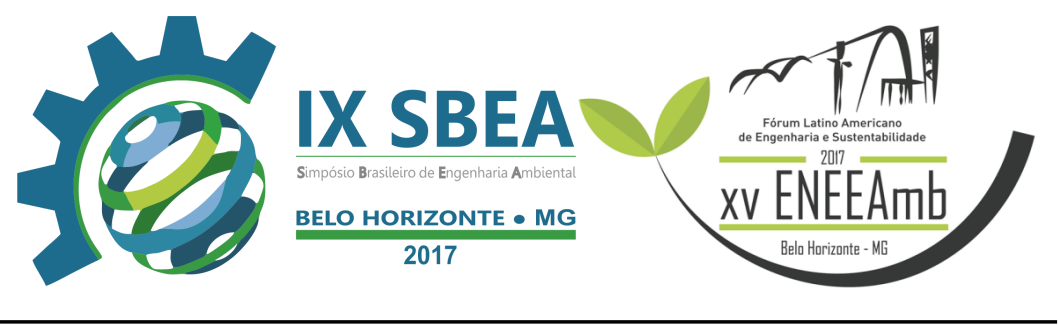

VELOSO, A. V. et al. Análise dimensional de um biodigestor piloto baseado no modelo indiano utilizando resíduos alimentares. In: CONGRESSO NACIONAL DE ENGENHARIA MECÂNICA,6., Campina Grande - Sergipe. 2010. 